\section{Violência sexual contra crianças e adolescentes: características relativas à vitimização nas relações familiares}

\author{
Sexual abuse of children and adolescents: \\ characteristics of sexual victimization \\ in family relations
}

\author{
1 Centro de Referência \\ da Criança e do Adolescente, \\ Ribeirão Preto, Brasil. \\ 2 Escola de Enfermagem \\ de Ribeirão Preto, \\ Universidade de São Paulo, \\ Ribeirão Preto, Brasil. \\ 3 Faculdade de Medicina \\ de Ribeirão Preto, \\ Universidade de São Paulo, \\ Ribeirão Preto, Brasil. \\ Correspondência \\ Jair Naves dos Reis \\ Faculdade de Medicina \\ de Ribeirão Preto, \\ Universidade de São Paulo. \\ Rua Tenente Catão Roxo \\ 2418, Ribeirão Preto, SP \\ 14051-140, Brasil. \\ jairnaves@netsite.com.br
}

\section{Abstract}

This study analyzes the characteristics of sexual abuse committed within the family against age groups classified according to the Brazilian Statute for Children and Adolescents (the prevailing legislation on matters pertaining to minors) and treated at the Reference Center for Children and Adolescents and the Guardianship Councils in Ribeirão Preto, São Paulo State, Brazil,from 1995 to 2000. Some 234 abuses were identified, committed by 217 aggressors, against 210 families and a total of 226 victims. A total of 131 children (48.7\%) and 95 adolescents (41.2\%), predominantly females, were victimized.Children ranging from 10 to 12 years were the most frequently abused (19.5\%), as well as adolescents from 12 to 14 years old (17.3\%). The majority of the victims live in families with 3 (19.9\%) or 4 children (177\%), and the firstborn are the most frequently abused (33.6\%). The majority of aggressors who acted alone victimized only one individual (86.7\%). Fathers (34.2\%) and stepfathers $(30.3 \%)$ were the most frequent aggressors, with the former victimizing more children (19.7\%) and the latter adolescents (17.1\%).

Violence; Sexual Child Abuse; Child Health; Teen Health
Márcia Aparecida Ribeiro 1

Maria das Graças Carvalho Ferriani 2 Jair Naves dos Reis 3

\section{Introdução}

A violência é hoje uma das grandes preocupações em nível mundial, afetando a sociedade como um todo, grupos ou famílias e ainda, o indivíduo de forma isolada. Fazendo parte da chamada questão social, ela revela formas de dominação e opressão desencadeadoras de conflitos. Como um fenômeno complexo, polissêmico e controverso, a violência é perpetrada por indivíduos contra outros indivíduos, manifestando-se de várias maneiras, assumindo formas próprias de relações pessoais, sociais, políticas ou culturais 1 .

Devido às suas características quantitativas e qualitativas, a violência é multifacetada e polimórfica, surgindo na sociedade por meio de ações que se interligam, interagem e se fortalecem ${ }^{2}$, possuindo como expressão concreta, os diferentes meios e métodos de coerção e dominação utilizados com a finalidade de conquistar, reter poder ou obter privilégios.

Inserida num contexto histórico-social e com profundas raízes culturais, a violência sexual, uma das facetas do fenômeno violência, atinge todas as faixas etárias, classes sociais e pessoas de ambos os sexos 3. Conforme se observa na literatura mundial, ela ocorre universalmente, estimando-se que produza cerca de 12 milhões de vítimas mulheres anualmente, atingindo desde recém-natos até idosos 4.

Devido a fatores como medo, falta de credibilidade no sistema legal e o silêncio cúmplice 
que envolve as vitimizações sexuais, as mesmas são de difícil notificação. Nos Estados Unidos, as denúncias junto às autoridades legais apresentam taxas varáveis de 16 a $32 \%$, com cerca de 300 a 350 mil pessoas com idade de 12 anos ou mais vitimizadas anualmente 5 , e igual número de vítimas com idade abaixo de 12 anos 6. No Brasil, inexistem dados globais a respeito do fenômeno, estimando-se que menos de $10 \%$ dos casos chegam às delegacias 7 .

Nas vitimizações sexuais, além das lesões físicas e genitais sofridas, as pessoas tornam-se mais vulneráveis a outros tipos de violência, aos distúrbios sexuais, ao uso de drogas, a prostituição, à depressão e ao suicídio. As vítimas enfrentam ainda, a possibilidade de adquirirem doenças sexualmente transmissíveis, o vírus da imunodeficiência humana (HIV) e o risco de uma gravidez indesejada decorrente do estupro. Diante dessa magnitude de eventos, a violência sexual adquiriu caráter endêmico, convertendo-se num complexo problema de saúde pública cujo enfrentamento torna-se um grande desafio para a sociedade 3,8 .

Ao organizar a sociedade, os seres humanos utilizam vários eixos de hierarquização, estabelecendo regras culturais, sociais, éticas e legais para reger o comportamento de indivíduos na coletividade. As regras de autoridade, gênero e idade são fatores de grande importância na análise das relações sociais e interpessoais da violência sexual dentro do espaço doméstico ou fora do mesmo. A regra da autoridade determina o domínio do mais forte sobre o mais fraco, enquanto que a de gênero, regula as relações entre homens e mulheres. A regra de idade, de um lado rege as relações entre crianças e adolescentes e, do outro, as relações entre adultos detentores do poder e desses sobre os primeiros, socialmente excluídos do processo decisório 9.

Na violência sexual doméstica, as vitimizações ocorrem no território físico e simbólico da estrutura familiar onde o homem praticamente possui o domínio total. Ela é definida por Deslandes 10 (p. 13), como "todo ato ou jogo sexual, relação heterossexual ou homossexual cujo agressor esteja em estágio de desenvolvimento psicossexual mais adiantado que a criança ou o adolescente com o intuito de estimulá-las sexualmente ou utilizá-las para obter satisfação sexual". No espaço doméstico, por um processo de domínio e poder estabelecido pelas regras sociais, agressores com laços consangüíneos ou de parentescos perpe- tram o tipo de violência sexual chamada de intrafamiliar 11.

Atualmente, a noção de cidadania requer que os membros da sociedade, reconhecidos como cidadãos de acordo com um marco legal democraticamente estabelecido, possuam o direito à liberdade, à participação, à garantia da vida, à sobrevivência e ao bem-estar. Rompendo antigos padrões societários, na década de 90, o Brasil realiza um importante avanço no campo dos direitos humanos, aprovando o Estatuto da Criança e do Adolescente 12. A partir de então, esses passaram a ser juridicamente considerados como sujeitos de direitos e não mais menores incapazes, objetos de tutela, de obediência e de submissão 13. Tendo como paradigma os recentes avanços da normativa internacional e possuindo como conteúdo o melhor da experiência acumulada pelo movimento social brasileiro, o Estatuto da Criança e do Adolescente é um instrumento que colabora decisivamente na identificação dos mecanismos e exigibilidade dos direitos constitucionais da população infanto-juvenil. Privilegiase nele, um espaço para a denúncia e o ressarcimento de qualquer fato que viole os direitos das crianças e adolescentes, ainda que à revelia dos mesmos 14 .

Nos dias atuais, a sociedade e o Estado brasileiros promovem o enfrentamento dos diversos tipos de violência, assegurando às crianças e adolescentes o pleno exercício de seus direitos constitucionais e estatutários. Nesse sentido, destacam-se no Município de Ribeirão Preto, São Paulo, as ações dos Conselhos Tutelares e do Centro de Referência da Criança e do Adolescente (CRCA). O Conselho Tutelar, órgão permanente e autônomo, não jurisdicional, tem como atribuição o atendimento direto de denúncias, o diagnóstico da realidade de violação de direitos, o monitoramento do Sistema de Garantia de Direitos e o atendimento direto de serviços, suprindo a falta de políticas públicas. O CRCA desenvolve, em parceria com o Ministério Público, um programa que prioriza o atendimento de crianças e adolescentes em situação de risco pessoal e social, segundo os preceitos estabelecidos pelo Estatuto da Criança e do Adolescente.

Nesse contexto, o presente estudo tem como objetivo analisar as características relativas às vitimizações sexuais intrafamiliares, cujas denúncias foram acolhidas em órgãos responsáveis pela defesa de direitos de crianças e adolescentes. 


\section{Métodos}

O presente estudo, retrospectivo, exploratório e descritivo, procedeu a análise de casos de violência sexual intrafamiliar contra crianças e adolescentes de ambos os sexos, documentados no CRCA e nos Conselhos Tutelares do Município de Ribeirão Preto, cujas denúncias foram registradas no período de 1o de janeiro de 1995 a 31 de dezembro de 2000.

Excluiu-se da análise os casos cujos prontuários não foram encontrados e aqueles provenientes de outros municípios e que, por motivos de atendimento médico em Ribeirão Preto e por força de lei, foram aqui denunciados. Foram excluídos também os casos que, apesar de registrados como violência sexual, referiamse apenas aos irmãos das vítimas, não tendo os mesmos sofrido vitimizações. Diante de duplicidade de prontuários entre as instituições, considerou-se um único caso, sendo as réplicas excluídas.

Por meio dos livros de registros dessas instituições, obteve-se a identificação das fichas de atendimento relativas aos casos de violência sexual, tornando possível a verificação de dados tais como: idade, sexo, número de filhos por família, características das vítimas enquanto filho, número de vítimas por família e vínculo com o agressor. À parte das considerações judiciárias onde os delitos contra a liberdade sexual são tipificados como crimes previstos no Código Penal, todos os casos foram englobados no termo violência sexual.

Para coleta de dados utilizou-se instrumento especificamente elaborado para esse fim. As informações obtidas foram transportadas para um banco de dados do programa Microsoft Access e posteriormente analisadas.

As vítimas foram categorizadas segundo o critério de idade estabelecido pelo Estatuto da Criança e do Adolescente que em seu Título I, Artigo 2o, reza ser criança a pessoa com até doze anos incompletos e adolescente aquela entre doze e dezoito anos de idade 12. Para melhor apreciação da faixa etária das vítimas, distribuiu-se suas idades em intervalos de dois anos até o limite previsto por aquele estatuto.

O estudo foi desenvolvido de acordo com os preceitos da Resolução 196/96 do Conselho Nacional de Saúde, sendo aprovado pelo Comitê de Ética em Pesquisa da Escola de Enfermagem de Ribeirão Preto da Universidade de São Paulo.

\section{Resultados}

No período estudado verificou-se a ocorrência de 554 casos de violência sexual, dos quais 328 foram excluídos por não se adequarem aos critérios previamente estabelecidos. Sofreram vitimizações 226 crianças e adolescentes pertencentes a 210 famílias, num total de 234 agressões perpetradas por 217 agressores.

Um maior número de casos envolveu crianças, constatando-se o predomínio de vítimas do sexo feminino em ambos os grupos etários. Crianças com idade entre dez anos e um mês a 12 incompletos foram as mais vitimizadas, seguidas daquelas com seis anos e um mês a dez anos completos. Nos adolescentes, a faixa etária mais atingida foi aquela entre 12 e 14 anos completos e 14 e 16 anos completos (Tabela 1).

À parte do expressivo contingente de registros sem informações, as vitimizações ocorreram em maior número nas famílias que possuíam três, quatro e dois filhos, respectivamente (Tabela 2).

Na maioria das famílias as práticas de violência sexual envolveram apenas uma vítima. Observa-se que um maior número de vitimizações únicas ocorreu em crianças, seguidas das adolescentes do sexo feminino (Tabela 3).

No círculo familiar, os primeiros e segundos filhos foram os mais vitimizados. Na distribuição segundo as faixas etárias, destacaramse os casos envolvendo primogênitas adolescentes e crianças (Tabela 4).

Pais e padrastos foram os responsáveis pelo maior número de vitimizações, identificandose os primeiros como responsáveis pelas agressões cometidas contra crianças e os segundos nas vitimizações perpetradas contra adolescentes (Tabela 5).

\section{Discussão}

No processo de análise, chamou a atenção a carência de informações nas fichas de atendimento das instituições pesquisadas a respeito de dados específicos envolvidos nas vitimizações sexuais, tais como os contidos nos laudos de exame médico-legal, nos boletins de ocorrência e relatórios médicos. E ainda, a não uniformidade de termos empregados para designar o fenômeno e a expressiva ausência de dados a respeito do agressor. $\mathrm{O}$ fato alerta para a necessidade de um atendimento contextualizado, no qual a ação profissional individualizada deve ceder espaço à implantação de uma rede que acolhe, trata, age e pensa de forma integrada. Nesse sentido, além da infra-estrutura 
Distribuição dos casos de violência sexual, segundo faixa etária e sexo das vítimas atendidas no Centro de Referência da Criança e do Adolescente (CRCA) e nos Conselhos Tutelares de Ribeirão Preto, São Paulo, Brasil, no período de 1995 a 2000.

\begin{tabular}{|c|c|c|c|c|c|c|}
\hline \multirow[t]{2}{*}{ Faixa etária } & \multicolumn{2}{|c|}{ Feminino } & \multicolumn{2}{|c|}{ Masculino } & \multicolumn{2}{|c|}{ Total } \\
\hline & $\mathrm{n}$ & $\%$ & $\mathrm{n}$ & $\%$ & $\mathrm{n}$ & $\%$ \\
\hline \multicolumn{7}{|l|}{ Criança } \\
\hline 0 a 2 anos completos & 6 & 2,7 & - & - & 6 & 2,7 \\
\hline 2 anos e 1 mês a 4 anos completos & 15 & 6,6 & 4 & 1,8 & 19 & 8,4 \\
\hline 4 anos e 1 mês a 6 anos completos & 15 & 6,6 & 3 & 1,3 & 18 & 8,0 \\
\hline 6 anos e 1 mês a 8 anos completos & 16 & 7,1 & 6 & 2,7 & 22 & 9,7 \\
\hline 8 anos e 1 mês a 10 anos completos & 20 & 8,8 & 2 & 0,9 & 22 & 9,7 \\
\hline 10 anos e 1 mês a 12 anos incompletos & 38 & 16,8 & 6 & 2,7 & 44 & 19,5 \\
\hline Subtotal & 110 & 48,7 & 21 & 9,3 & 131 & 58,0 \\
\hline \multicolumn{7}{|l|}{ Adolescente } \\
\hline 12 a 14 anos completos & 38 & 16,8 & 1 & 0,4 & 39 & 17,3 \\
\hline 14 anos e 1 mês a 16 anos completos & 37 & 16,4 & 1 & 0,4 & 38 & 16,8 \\
\hline 16 anos e 1 mês a 18 anos completos & 18 & 8,0 & - & - & 18 & 8,0 \\
\hline Subtotal & 93 & 41,2 & 2 & 0,9 & 95 & 42,0 \\
\hline Total & 203 & 89,8 & 23 & 10,2 & 226 & 100,0 \\
\hline
\end{tabular}

Fonte: Fichas do CRCA e Conselhos Tutelares.

necessária ao atendimento integral às vítimas de violência sexual, estariam presentes profissionais capacitados utilizando protocolos previamente definidos para atuação.

Apesar dos meninos serem também vítimas de violência sexual, a grande maioria dos casos envolveu crianças e adolescentes do sexo feminino. $\mathrm{O}$ fato foi igualmente observado por outros estudos nacionais restritos $15,16,17,18$ nos quais a mulher é a vítima preferencial desse tipo de agressão em 90 a 95\% dos casos, evidenciando a questão de gênero, onde as diferenças relativas ao sexo são convertidas em desigualdades, possibilitando o processo de dominação e exploração 19 .

Crianças com idade entre dez anos e um mês a 12 anos incompletos sofreram maior número de vitimizações (19,5\%), seguindo-se aquelas com seis anos e um mês a oito anos completos $(9,7 \%)$, e dessa idade até dez anos completos $(9,7 \%)$. Nos adolescentes, a faixa etária mais atingida foi aquela entre 12 anos e um mês e 14 anos completos (17,3\%) e 14 anos e um mês a 16 anos completos (16,8\%). De forma semelhante, Reis 18, utilizando o critério de idade estabelecido pelo Estatuto da Criança e do Adolescente, constatou um predomínio de vítimas adolescentes com idade entre 12 e 14 anos $(17,9 \%)$ e crianças com nove a 11 anos $(13,1 \%)$. Comparações com outros estudos tor-
Tabela 2

Distribuição dos casos de violência sexual atendidos no Centro de Referência da Criança e do Adolescente (CRCA) e nos Conselhos Tutelares de Ribeirão Preto, São Paulo, Brasil, segundo o número de filhos existentes nas famílias das vítimas, no período de 1995 a 2000.

\begin{tabular}{lrr}
\hline Número de filhos & $\mathbf{n}$ & $\%$ \\
\hline Um filho/a & 21 & 9,3 \\
Dois filhos/as & 35 & 15,5 \\
Três filhos/as & 45 & 19,9 \\
Quatro filhos/as & 40 & 17,7 \\
Cinco filhos/as & 19 & 8,4 \\
Acima de seis filhos/as & 12 & 5,3 \\
Sem informação & 54 & 23,9 \\
Total & 226 & 100,0 \\
\hline
\end{tabular}

Fonte: Fichas do CRCA e Conselhos Tutelares. 
Tabela 3

Distribuição dos casos de violência sexual, segundo o número de vítimas por família

nas faixas etárias analisadas, no período de 1995 a 2000

\begin{tabular}{|c|c|c|c|c|c|c|c|c|c|c|c|c|}
\hline \multirow{3}{*}{$\begin{array}{l}\text { Número de vítimas } \\
\text { por família }\end{array}$} & \multicolumn{4}{|c|}{ Crianças } & \multicolumn{4}{|c|}{ Adolescentes } & \multicolumn{4}{|c|}{ Total } \\
\hline & \multicolumn{2}{|c|}{ Feminino } & \multicolumn{2}{|c|}{ Masculino } & \multicolumn{2}{|c|}{ Feminino } & \multicolumn{2}{|c|}{ Masculino } & \multicolumn{2}{|c|}{ Feminino } & \multicolumn{2}{|c|}{ Masculino } \\
\hline & $\mathrm{n}$ & $\%$ & $n$ & $\%$ & $n$ & $\%$ & $n$ & $\%$ & $\mathrm{n}$ & $\%$ & $n$ & $\%$ \\
\hline Uma & 100 & 44,2 & 15 & 6,6 & 79 & 35,0 & 2 & 0,9 & 179 & 79,2 & 17 & 7,5 \\
\hline Duas & 8 & 3,5 & 3 & 1,3 & 9 & 4,0 & - & - & 17 & 7,5 & 3 & 1,3 \\
\hline Três & 2 & 0,9 & 3 & 1,3 & 1 & 0,4 & - & - & 3 & 1,3 & 3 & 1,3 \\
\hline Quatro & - & - & - & - & 4 & 1,8 & - & - & 4 & 1,8 & - & - \\
\hline Total & 110 & 48,7 & 21 & 9,3 & 93 & 41,2 & 2 & 0,9 & 203 & 89,8 & 23 & 10,2 \\
\hline
\end{tabular}

Fonte: Fichas do CRCA e Conselhos Tutelares de Ribeirão Preto.

Tabela 4

Distribuição dos casos de violência sexual, segundo sexo e posição da vítima como filho na família, nas faixas etárias analisadas, no período de 1995 a 2000.

\begin{tabular}{|c|c|c|c|c|c|c|c|c|c|c|c|c|}
\hline \multirow{3}{*}{$\begin{array}{l}\text { Posição da vítima } \\
\text { como filho } \\
\text { na família }\end{array}$} & \multicolumn{4}{|c|}{ Crianças } & \multicolumn{4}{|c|}{ Adolescentes } & \multicolumn{4}{|c|}{ Total } \\
\hline & \multicolumn{2}{|c|}{ Feminino } & \multicolumn{2}{|c|}{ Masculino } & \multicolumn{2}{|c|}{ Feminino } & \multicolumn{2}{|c|}{ Masculino } & \multicolumn{2}{|c|}{ Feminino } & \multicolumn{2}{|c|}{ Masculino } \\
\hline & $\mathrm{n}$ & $\%$ & $\mathrm{n}$ & $\%$ & $\mathrm{n}$ & $\%$ & $\mathrm{n}$ & $\%$ & $\mathrm{n}$ & $\%$ & $\mathrm{n}$ & $\%$ \\
\hline 1ㅇ filho & 30 & 13,3 & 7 & 3,1 & 38 & 16,8 & 1 & 0,4 & 68 & 30,1 & 8 & 3,5 \\
\hline 2o filho & 25 & 11,1 & 3 & 1,3 & 16 & 7,1 & - & - & 41 & 18,1 & 3 & 1,3 \\
\hline 3o filho & 12 & 5,3 & 3 & 1,3 & 9 & 4,0 & 1 & 0,4 & 21 & 9,3 & 4 & 1,8 \\
\hline 4o filho & 7 & 3,1 & 1 & 0,4 & 2 & 0,9 & - & - & 9 & 4,0 & 1 & 0,4 \\
\hline 5o filho & 3 & 1,3 & - & - & 1 & 0,4 & - & - & 4 & 1,8 & - & - \\
\hline Filho adotivo & 4 & 1,8 & - & - & - & - & - & - & 4 & 1,8 & - & - \\
\hline Filho único & 11 & 4,9 & 1 & 0,4 & 5 & 2,2 & - & - & 10 & 7,1 & 1 & 0,4 \\
\hline Sem Informação & 18 & 8,0 & 6 & 2,7 & 22 & 9,7 & - & - & 40 & 17,7 & 6 & 2,7 \\
\hline Total & 110 & 48,7 & 21 & 9,3 & 93 & 41,2 & 2 & 0,9 & 203 & 89,8 & 23 & 10,2 \\
\hline
\end{tabular}

Fonte: Fichas do CRCA e Conselhos Tutelares de Ribeirão Preto.

naram-se impraticáveis devido aos critérios de idade utilizados pelos autores com parâmetros definidos pela Organização Mundial da Saúde.

Não é apenas o desejo sexual o fator proeminente na motivação dos agressores sexuais, mas também o gênero, pois crianças e adolescentes fazem parte da categoria dominada e sujeita ao poder exercido pelo mais velho sobre o mais novo e do masculino sobre o feminino. Dessa forma, crianças e adolescentes como seres em desenvolvimento, psicológica e moralmente imaturos, não conseguem resistir a um familiar adulto que lhes impõe sua autoridade transformando-os em objetos sexuais. É nesse contexto, segundo Faleiros \& Faleiros 20, que subsiste a violência sexual de adultos contra crianças e adolescentes, onde o autoritaris- mo, o machismo e os preconceitos se articulam com as condições de vida das famílias e as questões de poder se manifestam nas relações afetivas e na sexualidade.

Nos dias de hoje, as oportunidades de bemestar variam de acordo com os tipos e estruturas familiares. As peculiaridades de cada família, tais como sua composição, condições de vida e a idade de seus componentes indicam vulnerabilidades potenciais. A instituição familiar sofre impactos de mudanças sociais, culturais e econômicas que redefinem sua organização. Por despender recursos econômicos com seus membros, as famílias tendem a possuir menor número de pessoas, de forma a serem capazes de manter suas necessidades sociais e humanas básicas. No Brasil, em 1970, o número total 
de filhos (taxa de fecundidade) era de 6,3 por mulher em idade fértil. Em 1980, este valor caiu para 4,3 alcançando a ordem de 2,6 filhos por mulher em 1995 21. Esta observação converge para os dados deste estudo que demonstram um maior número de vítimas em famílias compostas por três filhos. Apesar da violência sexual ocorrer em todos os níveis socioeconômicos, fatores tais como a miséria, facilitam as situações de promiscuidade, favorecendo as vitimizações.

Ao contrário do verificado em outros tipos de abuso que geralmente acometem mais de uma criança ou adolescente em seus incidentes, neste estudo, a violência sexual envolveu na sua maioria apenas uma vítima na família $(86,7 \%)$, sendo as crianças as mais visadas. Dados semelhantes são citados por Pimentel et al. 16, com $92 \%$ dos casos apresentando uma única vítima que na maioria (70\%) não tinha 18 anos à época dos fatos. Na família existem condições que a tornam proeminente nas situações de violência sexual, e nas crianças certas características que fazem delas vítimas potenciais desse tipo de abuso. No ambiente doméstico, os limites impostos pela privacidade isolam a família dos olhos e ouvidos do domínio público, proporcionando aos agressores um local no qual a violência sexual torna-se um crime perfeito, já que pode ser praticada sem testemunhas ou encoberta pelo silencio cúmplice.

Ainda que as crianças relatem a ocorrência de abusos sexuais, observa-se uma desqualificação das revelações verbais e não-verbais das vítimas, negando-se evidências em nome de fidelidades, sigilos profissionais e de justiça 20. Raramente uma criança mente deliberadamente sobre um abuso, exceto para negá-lo num processo em que a verdade é contida por meio de ameaças e seduções. Enquanto certas áreas do funcionamento familiar permanecem intactas, nas vitimizações sexuais as fronteiras intergeracionais se encontram rompidas e atravessadas pela desigualdade de gênero que faz com que crianças e adolescentes meninas sejam os alvos preferenciais dos agressores.

Conforme se observa, foram mais vitimizadas as adolescentes primogênitas $(16,8 \%)$, seguidas das crianças na mesma condição (13,3\%). Segundo Deslandes 10, é comum existir na família uma determinada criança ou adolescente como alvo principal de abusos devido às suas características pessoais ou a ela atribuídas pelo agressor. Embora outros filhos não estejam imunes a situações de violência doméstica, com freqüência o primogênito cumpre esse papel.

Busca-se identificar o perigo além do nosso espaço privado de convivência, correlacionan-
Tabela 5

Distribuição dos casos de violência sexual sofrida pelas vítimas, segundo a faixa etária das mesmas e vínculo com o agressor, no período de 1995 a 2000.

\begin{tabular}{lrrrrrr}
\hline \multirow{2}{*}{ Vínculo } & \multicolumn{2}{c}{ Criança } & \multicolumn{2}{c}{ Adolescente } & \multicolumn{2}{c}{ Total } \\
& \multicolumn{1}{c}{$\mathrm{n}$} & $\%$ & $\mathrm{n}$ & $\%$ & $\mathrm{n}$ & $\%$ \\
\hline Pai & 46 & 19,7 & 34 & 14,5 & 80 & 34,2 \\
Padrasto & 31 & 13,2 & 40 & 17,1 & 71 & 30,3 \\
Irmão & 14 & 6,0 & 1 & 0,4 & 15 & 6,4 \\
Tio & 19 & 8,1 & 8 & 3,4 & 27 & 11,5 \\
Avô & 10 & 4,3 & 2 & 0,9 & 12 & 5,1 \\
Primo & 8 & 3,4 & 1 & 0,4 & 9 & 3,8 \\
Outros familiares & 1 & 0,4 & 2 & 0,9 & 3 & 1,3 \\
Responsável legal & 5 & 2,1 & - & - & 5 & 2,1 \\
Sem informação & 5 & 2,1 & 7 & 3,0 & 12 & 5,1 \\
Total & 139 & 59,4 & 95 & 40,6 & 234 & 100,0 \\
\hline
\end{tabular}

Fonte: Fichas do CRCA e Conselhos Tutelares de Ribeirão Preto.

do-o com os pobres, os marginalizados e com a insegurança generalizada que existe no espaço público. Porém, atravessando a estratificação social, a violência sexual ocorre dentro dos lares, perpetrada por pessoas do circulo familiar, tornando o espaço doméstico um local inseguro para crianças e adolescentes. Os pais foram responsáveis pelo maior número de vitimizações sexuais $(34,2 \%)$ e os principais agressores de suas crianças $(19,7 \%)$, enquanto que os padrastos agrediram mais suas enteadas adolescentes $(17,1 \%)$. Outros componentes da família, tais como tios $(11,5 \%)$ e irmãos $(6,4 \%)$ também aparecem como agressores sexuais. Esses achados contrastam com aqueles encontrados por Reis 18 , que relata o pai biológico como perpetrador em $28,2 \%$ dos casos, padrastos em $30,8 \%$ e tios em $6,7 \%$. Esse autor ainda constata que os padrastos foram responsáveis por um maior número de casos envolvendo adolescentes $(14,7 \%)$ e uma igual distribuição com os pais nas crianças $(16,1 \%)$.

Apesar da sociedade ressaltar a importância da família, historicamente sua organização não se fez sob os princípios fundamentais de respeito à pessoa humana, configurando-se como um espaço da hierarquia e da subordinação caracterizado pelo domínio dos homens sobre as mulheres e de adultos sobre as crianças.

A violência interpessoal de caráter sexual contra crianças e adolescentes, nesse sentido, é uma violação de direitos humanos, sexuais e dos direitos particulares de pessoa em desenvolvimento. A violência sexual intrafamiliar constitui uma violação ao direito de uma convivência familiar protetora e uma ultrapassa- 
gem dos limites estabelecidos pelas regras sociais, culturais e familiares. Por tratar-se de uma transgressão, legalmente configura o ato delituoso, tipificando-o como crime. Após a formulação da denúncia, por meio da instauração de processo e julgamento, promove-se a responsabilização legal dos agressores, desencadeando-se ações ou punições legais pelo crime cometido. A notificação de casos de violência sexual aos Conselhos Tutelares é obrigatória segundo o Estatuto da Criança e do Adolescente. Ao receber a denúncia, estabelece-se um circuito fundamental na proteção das vítimas, uma vez que tais Conselhos possuem como funções, a defesa e garantia de direitos, tendo o poder de determinar por força de lei as ações de atendimento e de responsabilização. Contudo, entendendo que a resolubilidade é a realização de atendimento adequado visando a proteção das violações de direitos, observa-se que esses Conselhos apresentam deficiência de resolubilidade uma vez que em muitos locais, os conselheiros assumem seus cargos sem a devida capacitação, demonstrando pouco conhecimento a respeito do Estatuto da Criança e do Adolescente e do trabalho prático com ele. Suas ações não costumam ser planejadas, pautando-se por questões pontuais, com intervenções muitas vezes fragmentadas e de cunho emergencial, onde direciona-se o atendimento ao cuidado dos ferimentos sofridos ou ainda, ao tratamento psicoterápico ou a aplicação de medidas de proteção. Além de enfrentarem tais situações no dia-a-dia, os Conselhos Tutelares deparam-se com a falta de condições infra-estruturais e de retaguarda, sofrendo relações de conflito com outros órgãos que atuam no atendimento às vítimas 20,22.

Para Furniss 23, os casos de vitimizações de crianças e adolescentes por irmãos mais velhos podem ser compreendidos de maneira muito semelhante ao abuso por parte de pais e de figuras paternas, já que esses agressores no final da adolescência ou na idade adulta jovem estão na posição de autoridade quase parental.

A literatura relata que não há um único tipo de abusador, existindo entre eles um alto grau de variabilidade em termos de seus perfis pessoais, experiências de vida, histórias criminais e razão para o abuso.

Na complexa caracterização dos agressores sexuais de crianças e adolescentes, fatores comportamentais importantes podem ser citados, dentre eles, o foco sexual, a vitimização dos mesmos na infância e as influências negativas ocasionadas por falhas interpessoais e sociais durante o seu desenvolvimento. O foco sexual dos agressores compreende dois componentes: a intensidade do interesse pedofílico na qual o agressor está focado ou "fixado" em crianças e adolescentes como objetos sexuais e a exclusividade de sua preferência para tê-los como satisfação de seus desejos sexuais. A maioria das vítimas de abuso sexual na infância não se tornam agressores sexuais na idade adulta. Contudo, a vitimização sexual nessa fase da vida se acompanhada por fatores tais como o abuso físico, a duração do abuso sofrido e a relação com o perpetrador, pode contribuir para o surgimento de um futuro agressor. No contexto do desenvolvimento, a alta rotatividade de pessoas relacionadas aos cuidados na infância é tida como um poderoso preditor do grau de violência sexual expressa na idade adulta. Esta inconstância de pessoas que dispensam cuidados primários interfere com o desenvolvimento das habilidades de relacionamento, incrementando a probabilidade de desordens afetivas caracterizadas pela ansiedade intensa, insegurança e desconfiança. Tais experiências podem levar a déficits interpessoais e baixa auto-estima que minam severamente o desenvolvimento de um relacionamento adulto seguro. Indivíduos que sofreram essas falhas interpessoais e sociais estão mais propensos a se voltarem para as crianças para satisfazerem suas necessidades psicossexuais 24 .

Assim, ainda que a violência sexual seja um fenômeno histórico-social imiscuído nas relações cotidianas, revelando a existência das relações de poder, da desigualdade de gênero e de meios de coerção, observa-se que por trás de agressores do sexo masculino que exercem o domínio e posse sobre mulheres e crianças, existem características e experiências pessoais de vida que os levam a cometer vitimizações sexuais.

\section{Conclusão}

Na violência sexual intrafamiliar, a criança ou adolescente do sexo feminino se mostra como vítima preferencial dos agressores sexuais, encontrando-se inserida numa estrutura na qual sofre relações de poder expressas por um lado pela capacidade física, mental e social do agressor, e por outro, pela sua imaturidade, submissão à autoridade paterna e dos mais velhos, e à desigualdade de gênero.

Mesmo que nas vitimizações exista o exercício de poder e domínio, as situações de violência sexual intrafamiliar originam-se da utilização irresponsável de condições como as diferenças físicas e de idade, do grau de maturidade psicológica, da capacidade social e das razões que motivam a agressão em termos in- 
terpessoais. Por essas características, a violência sexual abrange o campo da moral e da proteção aos direitos humanos e sexuais, já que ela compromete o crescimento e desenvolvimento de crianças e adolescentes, produzindo seqüelas e uma matriz reprodutora que insere futuros agressores no círculo da violência.

\section{Resumo}

O objetivo deste estudo é analisar as características relativas às vitimizações sexuais intrafamiliares cometidas contra grupos etários categorizados segundo o critério de idade estabelecido pelo Estatuto da Criança e do Adolescente, atendidos no Centro de Referência da Criança e do Adolescente e nos Conselhos Tutelares de Ribeirão Preto, São Paulo, no período de 1995 a 2000. Identificou-se 234 agressões cometidas por 217 agressores contra 210 famílias e 226 vítimas. Foram vitimizadas 131 crianças $(48,7 \%)$ e 95 adolescentes $(41,2 \%)$ com predomínio do sexo feminino. Crianças com idade entre dez anos e um mês e 12 anos incompletos foram as mais atingidas (19,5\%) e nos adolescentes, entre 12 e 14 anos completos (17,3\%). A maioria das vítimas reside com famílias que possuem três (19,9\%) ou quatro filhos (17,7\%), sendo os primogênitos os mais agredidos (33,6\%). Agressores únicos vitimizaram em sua maioria apenas uma vítima (86,7\%). Pais $(34,2 \%)$ e padrastos (30,3\%) foram os que mais agrediram,com os primeiros vitimizando mais crianças $(19,7 \%)$ e os segundos, adolescentes (17,1\%).

Violência; Maus-Tratos Sexuais Infantis; Saúde Infantil; Saúde do Adolescente

\section{Colaboradores}

M. A. Ribeiro realizou o levantamento de dados e participou da definição dos métodos empregados, da pesquisa bibliográfica, da análise dos dados e da estruturação do artigo. M. G. C. Ferriani auxiliou na elaboração metodológica. J. N. Reis auxiliou na coleta de dados, participou da definição dos métodos empregados, da pesquisa bibliográfica, da análise dos dados e da estruturação do artigo, e realizou a transcrição do resumo para a língua inglesa.

\section{Referências}

1. Minayo MCS, Souza ER. É possível prevenir a violência? Reflexões a partir do campo da saúde pública. Ciênc Saúde Coletiva 1999; 4:7-23.

2. Cruz Neto O, Moreira MR. A concretização de políticas públicas em direção à prevenção da violência estrutural. Ciênc Saúde Coletiva 1999; 4: 33-52.

3. Ministério da Saúde. Prevenção e tratamento dos agravos resultantes da violência sexual contra mulheres e adolescentes. Brasília: Ministério da Saúde; 1999.

4. Beebe DK. Sexual assault: the physicians role in prevention and treatment. J Miss State Med Assoc 1998; 39:366-9.

5. Rennison CM. Criminal victimization -1997 to 1998. Washington DC: Bureau of Justice StatisticsNational Crime Victimization Survey, U.S. Department of Justice; 1999.

6. Sediak AJ, Broadhurst DD. Executive summary of the third national incidence study of child abuse and neglect. Washington DC: Administration for children and families, U.S. Department of Health and Human Services; 1996.

7. Faúndes A, Andalaf Neto J, Freitas F. II Fórum interprofissional sobre o atendimento ao aborto previsto na lei. Femina 1998; 26:134-8.

8. Organização Pan-Americana da Saúde. Resolução XIX: violência e saúde. Washington DC: Organização Pan-Americana da Saúde; 1993.

9. Saffioti HIB. No fio da navalha: violência contra criança e adolescente no Brasil atual. In: Madeira FR, organizador. Quem mandou nascer mulher? Estudos sobre crianças e adolescentes pobres no Brasil. Rio de Janeiro: Editora Record/Rosa dos Tempos; 1997. p. 135-211.

10. Deslandes SF. Prevenir a violência - um desafio para profissionais de saúde. Rio de Janeiro: Editora Fiocruz; 1994. 
11. Saffioti HIB. Já se mete a colher em briga de marido e mulher. São Paulo em Perspectiva 1999; 13: 82-91.

12. Lei no 8.069. Estatuto da Criança e do Adolescente. Brasília: Ministério do Bem-Estar Social; 1993.

13. Ministério da Justiça. Plano nacional de enfrentamento da violência sexual infanto-juvenil. Brasília: Ministério da Justiça; 2001.

14. Fundo das Nações Unidas para a Infância. Violência contra crianças e adolescentes. In: A infância brasileira nos anos 90. Brasília: Fundo das Nações Unidas para a Infância; 1998. p. 137-50.

15. Cohen C, Matsuda NE. Crimes sexuais e sexologia forense: estudo analítico. Rev Paul Med 1991; 109:157-64.

16. Pimentel S, Schritsmeyer ALP, Pandjiarjian V. Estupro: crime ou "cortesia"? Abordagem sociojurídica de gênero. Porto Alegre: Safe Editora; 1998.

17. Articulação de Mulheres Brasileiras. Políticas públicas para mulheres no Brasil: balanço nacional cinco anos após Beijing. Brasília: Articulação de Mulheres Brasileiras; 2000.

18. Reis JN. Violência sexual contra mulheres: análise de dados relacionados ao estupro e atentado violento ao pudor legalmente registrados em Ribeirão Preto-SP [Dissertação de Mestrado]. Ribeirão Preto: Faculdade de Medicina de Ribeirão Preto, Universidade de São Paulo; 2001.
19. Saffioti HIB, Almeida S. Violência de gênero - poder e impotência. Rio de Janeiro: Editora Revinter; 1995.

20. Faleiros VP, Faleiros ETS. Circuito e curtos-circuitos: atendimento, defesa e responsabilização do abuso sexual contra crianças e adolescentes. São Paulo: Editora Veras; 2001.

21. Fundo das Nações Unidas para a Infância. O processo demográfico brasileiro. In: A infância brasileira nos anos 90. Brasília: Fundo das Nações Unidas para a Infância; 1998. p. 13-28.

22. Fundo das Nações Unidas para a Infância. O processo demográfico brasileiro. In: A sociedade civil na promoção dos direitos das crianças e adolescentes. Brasília: Fundo das Nações Unidas para a Infância; 1998. p. 151-70.

23. Furniss T. Abuso sexual da criança: uma abordagem multidisciplinar. Porto Alegre: Editora Artes Médicas; 1993.

24. Prentky RA, Knigth RA, Lee AFS. Child sexual molestation: research issues. Washington DC: U.S. Department of Justice; 1997.

Recebido em 06/Nov/2002

Versão final reapresentada em 30/Jun/2003

Aprovado em 23/Out/2003 